\title{
EFFECT OF HIGH CHOLESTEROL DIET ON PLATELET AGGREGATION IN GUINEA PIGS
}

\author{
Kouichi Yoshida, Toshimichi Tsubor, Buichi FuJITANI, \\ Kazuko SHuri, and Masanao SHIMIzU ${ }^{1}$ \\ Research Laboratory, Dainippon Pharmaceutical Co., Ltd., \\ Enoki-cho, Suita, Osaka 564
}

(Received April 19, 1976)

\begin{abstract}
Summary Male guinea pigs fed a cholesterol diet for 1-8 weeks showed a marked increase in platelet aggregation induced by ADP. Analyses of lipids indicated that dietary cholesterol resulted in highly significant increases in plasma cholesterol, $\beta$-lipoprotein and phospholipid levels, and platelet cholesterol contents. Plasma triglyceride levels in cholesterol-fed animals increased significantly only at the 8th week of feeding. Platelet phospholipid levels in cholesterol-fed animals increased significantly at the 2 nd and 4 th week of feeding. There were statistically insignificant increases in plasma and platelet free fatty acid. Fibrinogen levels in cholesterol-fed animals showed an increase at the 2nd and 4th week of feeding, but clotting tests, such as prothrombin time, recalcification time and Stypven time, were not changed. When platelets from animals fed on a control diet were exposed to plasma from cholesterolfed animals, there was a notable increase in platelet aggregation in comparison with plasma from animals fed on a control diet. An increase of platelet aggregation was also observed, when platelets from cholesterolfed animals were mixed with the plasma from not only cholesterol-fed animals but also animals fed on a control diet. As the cholesterol in plasma and platelets was assumed to be a possible factor in the increase of platelet aggregation, $\beta$-lipoproteins (cholesterol-rich proteins) were isolated from plasma of cholesterol-fed animals and animals fed on a control diet, and $\beta$-lipoprotein fractions were found to cause a marked increase in platelet aggregation induced by ADP. The results of this study indicate that cholesterol feeding causes an increase of platelet aggregation, and that the causative factor of the increase is assumed to be $\beta$-lipoproteins.
\end{abstract}

A relationship between a high dietary intake of lipids and an increase of platelet aggregation has been shown clinically as well as experimentally (1-3).

1 吉田耕一，坪井俊紀，藤谷武一，修理一子，清水当尚 
Recently, SANO et al. (4) reported that platelet aggregation induced by ADP was enhanced after oral administration of cholesterol in rabbits, and OVERSOHL et al. (5) showed that a high cholesterol diet caused the enhancement of platelet aggregation accompanied with high levels of plasma cholesterol and triglyceride in rabbits. However, the mechanism by which dietary cholesterol influences platelet aggregation is not well understood.

The present study was undertaken to correlate dietary cholesterol with platelet function in guinea pigs, and to determine the possible plasma factor which causes the increase of platelet aggregation.

\section{MATERIALS AND METHODS}

Animals. Male Hartley strain guinea pigs with initial body weights of 280$320 \mathrm{~g}$ were used throughout the experiments. Guinea pigs were housed in individual cages and given tap water and food ad libitum. The animals were grouped and fed on the following diets for 1-8 weeks: group 1, a control diet (RC-4, Oriental Yeast Co., Ltd., Japan) and group 2, a cholesterol diet (a control diet containing $1 \%$ cholesterol).

Preparation of blood. Blood was taken by cardiac puncture with 20-gauge needle while the animal was under anesthesia with pentobarbital $(40 \mathrm{mg} / \mathrm{kg})$. Blood samples were collected in plastic disposable syringes containing 0.1 volume of $3.8 \%$ sodium citrate, $2.0 \%$ sodium oxalate or $1 \%$ disodium ethylenediaminetetraacetic acid dissolved in physiological saline (EDTA-saline). A suitable anticoagulant was chosen for each experiment. Immediately after collection, the syringe was inverted several times in order to mix blood with the anticoagulant. For isolation of $\beta$-lipoproteins, blood was harvested without any anticoagulant and serum was collected after coagulation on a Petri dish.

Platelet aggregation. Citrated blood was centrifuged at $120 \mathrm{~g}$ for $10 \mathrm{~min}$ at room temperature to yield platelet-rich plasma (PRP), kept at room temperature and used within $3 \mathrm{hr}$ after collection. Platelet-poor plasma (PPP) was obtained by centrifugation at $1,100 \mathrm{~g}$ for $10 \mathrm{~min}$. The platelet concentration of PRP was adjusted to $6-7 \times 10^{5}$ cells $/ \mathrm{mm}^{3}$ with PPP from the same specimen. An aliquot of PPP was used for the determination of lipid content.

Platelet aggregation studies were performed by the turbidimetric technique of BoRN ( 6 ) using an aggregometer (AG-2, Bryston Manufacturing Ltd., Canada) and a potentiometric recorder (B-161, Rikadenki Kogyo Co., Ltd.). PRP (0.665 ml) in a series of cuvettes was incubated at $37^{\circ} \mathrm{C}$ for $10 \mathrm{~min}$ and then an aggregation reaction was started by adding $0.035 \mathrm{ml}$ of ADP (sodium salt, Sigma Chemical Co., USA) solution to yield the final concentration of $2-40 \times 10^{-7} \mathrm{M}$ with continuous stirring $(1,100 \mathrm{rpm})$ by a magnetic stirrer. Aggregation of platelets produced changes in light transmission which were traced with the recorder. ADP was freshly dissolved in physiological saline immediately before use and kept in an ice- 
cold bath during an experiment. For testing the effect of $\beta$-lipoproteins on platelet aggregation, PRP $(0.63 \mathrm{ml})$ and various concentrations of $\beta$-lipoproteins suspended in physiological saline $(0.035 \mathrm{ml})$ were mixed and incubated at $37^{\circ} \mathrm{C}$ for $10 \mathrm{~min}$. Then, platelet aggregation tests were performed by the method mentioned above. In the control experiments, physiological saline instead of $\beta$-lipoproteins was used. A little elimination of the volume of PRP $(0.035 \mathrm{ml})$ in order to add $\beta$-lipoproteins showed no significant influence on the results of platelet aggregation.

Guinea pig platelet aggregation induced by ADP showed a typical biphasic aggregation pattern, as shown in Fig. 1. The ADP concentrations added and the incidence of irreversible platelet aggregation showed a linear relationship (Fig. 2) within the incidence being lower than $80 \%$. Therefore, platelet sensitivity to aggregation by ADP was assessed by the ADP concentrations which induced $50 \%$ incidence of irreversible aggregation of platelets. In vitro effect of $\beta$-lipoproteins on platelet aggregation by ADP was assessed both by the minimum concentration inducing irreversible platelet aggregation at $5 \times 10^{-7} \mathrm{M}$ of ADP which caused only reversible aggregation by itself, and by the time from the addition of ADP to the occurrence of irreversible aggregation.

Platelet-plasma crossover experiment. Platelets in PRP prepared from citrated blood were isolated by the modified method of WALSH (7) and resuspended as soon as possible in arbitrary PPP prepared from animals fed on a control diet or cholesterol-fed animals. Resuspended PRP was kept at a room temperature until used. Platelet-plasma crossover experiments were performed using the following procedures.

1. Platelets from control animals were resuspended in PPP from control ones.

2. Platelets from control animals were resuspended in PPP from cholesterolfed ones.

3. Platelets from cholesterol-fed animals were resuspended in PPP from control ones.

4. Platelets from cholesterol-fed animals were resuspended in PPP from cholesterol-fed ones.

Resuspended PRP was incubated at $37^{\circ} \mathrm{C}$ for $10 \mathrm{~min}$ and challenged with $1.5 \times 10^{-6} \mathrm{M}$ ADP. It took less than $1 \mathrm{hr}$ from resuspension of platelets in PPP to completion of crossover experiments. Within this time, little change on platelet aggregation by ADP was observed.

Extraction of platelet lipids. Platelet-rich plasma prepared from blood anticoagulated with EDTA-saline by centrifugation $(120 \mathrm{~g}, 10 \mathrm{~min})$ was centrifuged at $1,000 \mathrm{~g}$ for $15 \mathrm{~min}$. The platelet button obtained was carefully resuspended in $5 \mathrm{~mm}$ Tris buffer ( $\mathrm{pH} 7.4$ ) containing $154 \mathrm{~mm} \mathrm{NaCl}$ and $1 \mathrm{~mm}$ EDTA. The procedure was repeated 3 times to obtain the platelet suspension containing $5-20 \times 10^{5}$ cells $/ \mathrm{mm}^{3}$. The platelet suspension was centrifuged again at $2,000 \mathrm{~g}$ for $20 \mathrm{~min}$ and the final platelet button was mixed with chloroform-methanol $(2: 1)$. 
Then, lipids in platelets were extracted by the method of FolCH et al. (8).

Platelet count. The number of platelets was counted using a microcellcounter (CC1002, Toa Medical Electronics Co., Ltd., Japan) by the method of DeGUCHI et al. (9).

Clotting test. Aliquots of oxalated blood was taken off for platelet counts and hematocrit estimations (10). The rest of the blood samples was used for the determination of prothrombin time (PT) (11) and recalcification time (RCT)(12). Platelet factor-3 ( $\mathrm{PF}-3)$ availability was evaluated according to the method of SpeAt and Cintron (13) on PRP $\left(3 \times 10^{5}\right.$ cells $\left./ \mathrm{mm}^{3}\right)$ activated by ADP $\left(2 \times 10^{-4} \mathrm{M}\right)$. Reduction in Stypven clotting time after $20 \mathrm{~min}$ of incubation at $37^{\circ} \mathrm{C}$ was taken as an indicator of PF-3 availability. For the clotting tests, the end-point of clotting was determined with a coagulometer (Fibrometer, Kowa-Kizai Co., Ltd., Japan).

$\beta$-Lipoprotein. $\beta$-Lipoproteins in serum were isolated by the method of SAKAGAMI and ZILVERSMIT (14). The final $\beta$-lipoprotein preparation suspended in physiological saline was homogenous in celluloseacetate-electrophoresis (15). Concentrations of $\beta$-lipoproteins were shown by cholesterol contents in $\beta$-lipoproteins. Cholesterol contents in $\beta$-lipoproteins isolated from cholesterol-fed animals were the same as those from animals fed on a control diet.

Chemical analysis. Total and free cholesterols in plasma and platelets were determined by the methods of ZAK (16), and ZAK and DICKENMAN (17), respectively. Phospholipids in plasma and platelets were determined by the method of HENMI et al. (18). Plasma triglycerides (TG) were measured by the method of VAN HANDEL and Zilversmit (19). Proteins in platelets were estimated by the method of LOWRY et al. (20). Fibrinogen in plasma was measured by the tyrosine method (21).

$\beta$-Lipoproteins in serum were extracted by the heparin- $\mathrm{CaCl}_{2}$ precipitation method (22) and cholesterol contents in the $\beta$-lipoprotein preparations were assayed by the method of ZAK (16). Concentrations of $\beta$-lipoproteins were expressed as cholesterol contents in $\beta$-lipoproteins.

Free fatty acids (FFA) in plasma and platelets were separated by thin-layer chromatography (23). FFA areas on the chromatograms were scraped off and FFA was extracted with chloroform followed by methylation with diazomethanemethanol $(1: 1 \mathrm{v} / \mathrm{v})$. Benzophenone was used as an internal standard. Conditions of gas chromatography were as follows: column dimension, $100 \times 0.2 \mathrm{~cm}$; solid support, Chromosorb W (80-100 mesh); stationary phase, polydiethyleneglycolsuccinate $10 \%$; temperature, $170^{\circ} \mathrm{C}$; carrier gas, helium $0.82 \mathrm{~kg} / \mathrm{cm}^{2}$; detector, flame ionization detector.

\section{RESULTS}

Effect of dietary cholesterol on platelet aggregation

Typical aggregation patterns of platelets from guinea pigs fed on a control 
diet are shown in the Fig. 1 . ADP at $10^{-6} \mathrm{M}$ induced reversible aggregation, and $2.0 \times 10^{-6}$ and $3.0 \times 10^{-6} \mathrm{M}$ of ADP induced irreversible aggregation.

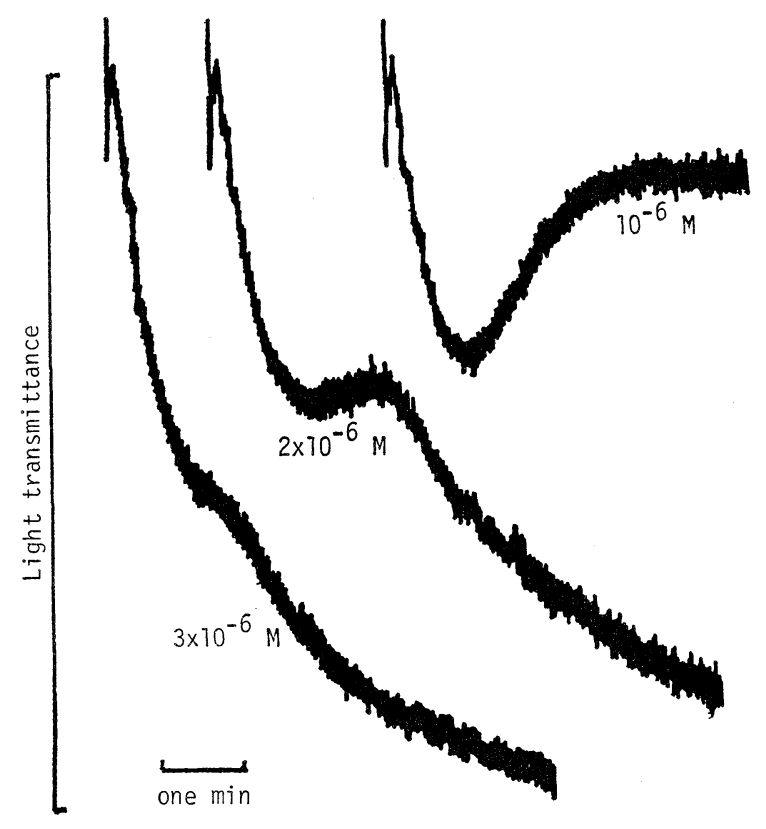

Fig. 1. Platelet aggregation patterns induced by ADP.

A high cholesterol diet enhanced the response of platelets to ADP in guinea pigs, as shown in Fig. 2. An ADP concentration which induced $50 \%$ incidence of irreversible aggregation of platelets was $17 \times 10^{-7} \mathrm{M}$ in animals fed on a control diet, and $10 \times 10^{-7}, 6 \times 10^{-7}, 5 \times 10^{-7}$ and $3 \times 10^{-7} \mathrm{M}$ in cholesterol-fed animals for $1,2,4$ and 8 weeks, respectively.

\section{Platelet-plasma crossover experiment}

When platelets from guinea pigs fed on a control diet were exposed to PPP from animals fed on a cholesterol diet, ADP at $1.5 \times 10^{-6} \mathrm{M}$ induced irreversible aggregation (Fig. 3-B), while only reversible aggregation by ADP was observed when platelets from animals fed on a control diet were mixed with PPP from animals fed on a control diet (Fig. 3-A). Irreversible aggregations were also observed, when platelets from cholesterol-fed animals were mixed with PPP from either animals fed on a control or a cholesterol diet (Fig. 3-C, D).

\section{Effect of dietary cholesterol on plasma and platelet lipids}

Plasma lipids. Guinea pigs fed on a cholesterol diet had significantly elevated cholesterol (total and free), $\beta$-lipoprotein and phospholipid levels as compared 


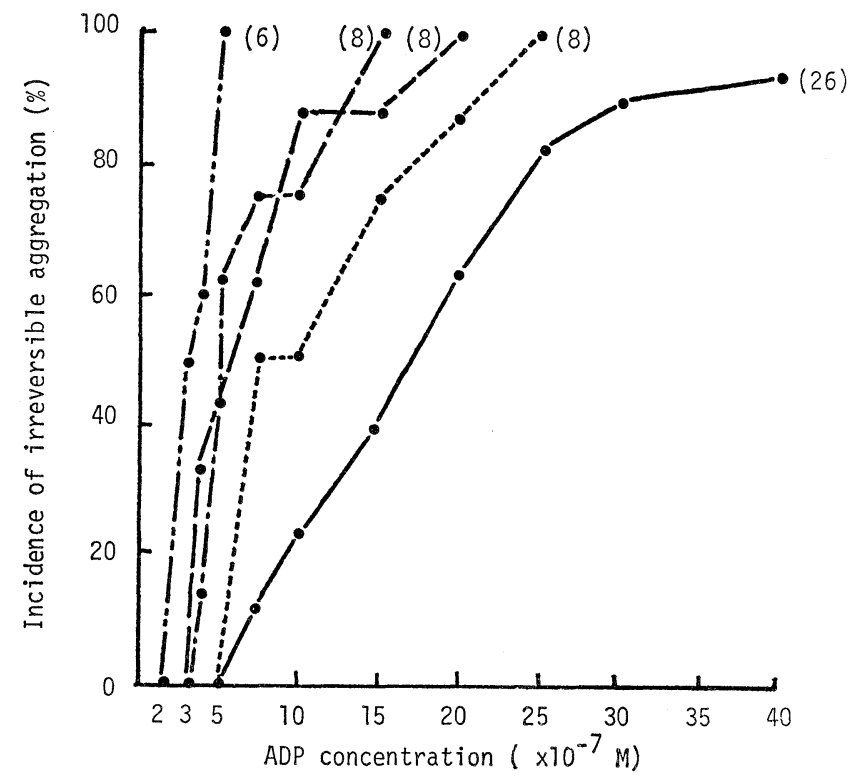

Fig. 2. Effect of dietary cholesterol on platelet aggregation induced by ADP.

diet; --- cholesterol diet for one week; - - - cholesterol diet for 2 weeks; --.cholesterol diet for 4 weeks; -.-- cholesterol diet for 8 weeks. Figures in parentheses show the number of animals used.

with animals fed on a control diet. TG levels in cholesterol-fed animals increased significantly only at the 8th week in comparison with those in animals fed on a control diet (Fig. 4). Only small differences (not significant statistically) of FFA levels were found between animals fed on a cholesterol and a control diet (Table 1).

Platelet lipids. As shown in Fig. 5, guinea pigs fed on a cholesterol diet had a notable increase of cholesterol (total and free) contents. Phospholipid contents showed a significant increase only at the period from the 2 nd to 4 th week of a cholesterol diet feeding. FFA levels in animals fed on a cholesterol diet showed an increasing tendency which was not significant statistically (Table 1).

\section{Effect of dietary cholesterol on blood coagulation}

As shown in Table 2, fibrinogen in animals fed on a cholesterol diet for 2-8 weeks was kept at higher levels than in animals fed on a control diet. On the other hand, dietary cholesterol did not show any influence on the number of platelets, hematocrit, PT, RCT and Stypven time.

\section{Enhancing effect of $\beta$-lipoproteins on platelet aggregation}

Figure 6 shows the results of the effect of $\beta$-lipoproteins on platelet aggregation induced by $5 \times 10^{-7} \mathrm{M}$ of ADP. The addition of more than $13 \mu \mathrm{g}$ as cholesterol $/ \mathrm{ml}$ (final concentration) of $\beta$-lipoproteins to PRP induced typical irreversible aggre- 


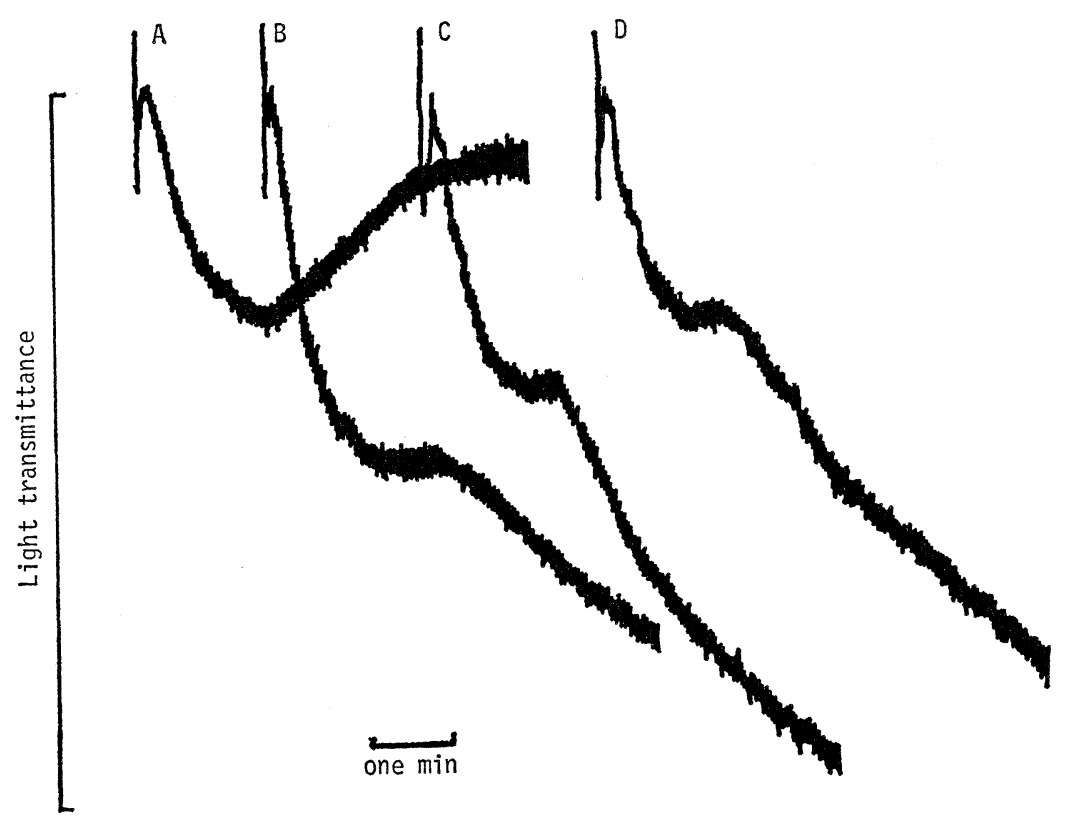

Fig. 3. Changes of platelet response to $\operatorname{ADP}\left(1.5 \times 10^{-6} \mathrm{M}\right)$ in platelet-plasma crossover experiment. A, platelets from animals fed on a control diet + PPP from animals fed on a control diet; B, platelets from animals fed on a control diet + PPP from cholesterol-fed animals; C, platelets from cholesterol-fed animals + PPP from animals fed on a control diet; D, platelets from cholesterol-fed animals + PPP from cholesterol-fed animals.

gation, though ADP at the concentration used caused only reversible aggregation. At $13 \mu \mathrm{g}$ as cholesterol $/ \mathrm{ml}$ of $\beta$-lipoproteins, the time from the addition of ADP to the appearance of irreversible aggregation was $5.20 \mathrm{~min}$ when $\beta$-lipoproteins from cholesterol-fed animals were used, and $5.04 \mathrm{~min}$ when $\beta$-lipoproteins from animals fed on a control diet were used. Increasing concentrations of $\beta$-lipoproteins resulted in gradual shortening of the time when irreversible aggregation occurred. This result suggests the enhancement of ADP-induced platelet aggregation by $\beta$-lipoproteins. $\beta$-Lipoprotein preparations isolated from both animals fed on a cholesterol diet and a control diet showed the same enhancing effect on platelet aggregation induced by ADP.

\section{DISCUSSION}

Recently, the pathogenesis of atherosclerosis has been focussed on the platelets (24). Various investigators have demonstrated increases of platelet aggregation or adhesion in a hyperlipidemic state by using various methods of measuring platelet function: the turbidity method $(1,2)$, the determination of a minimum 

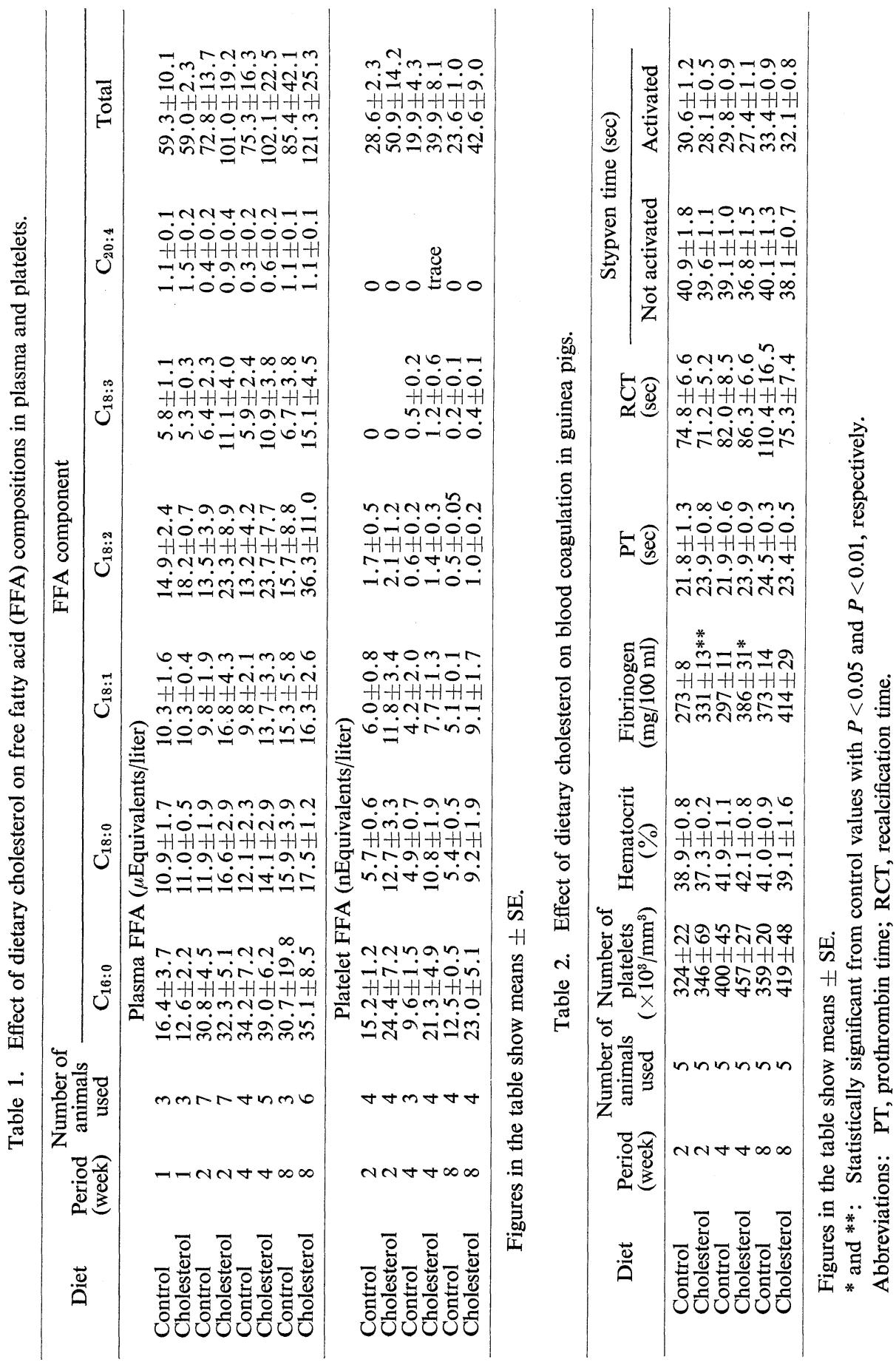

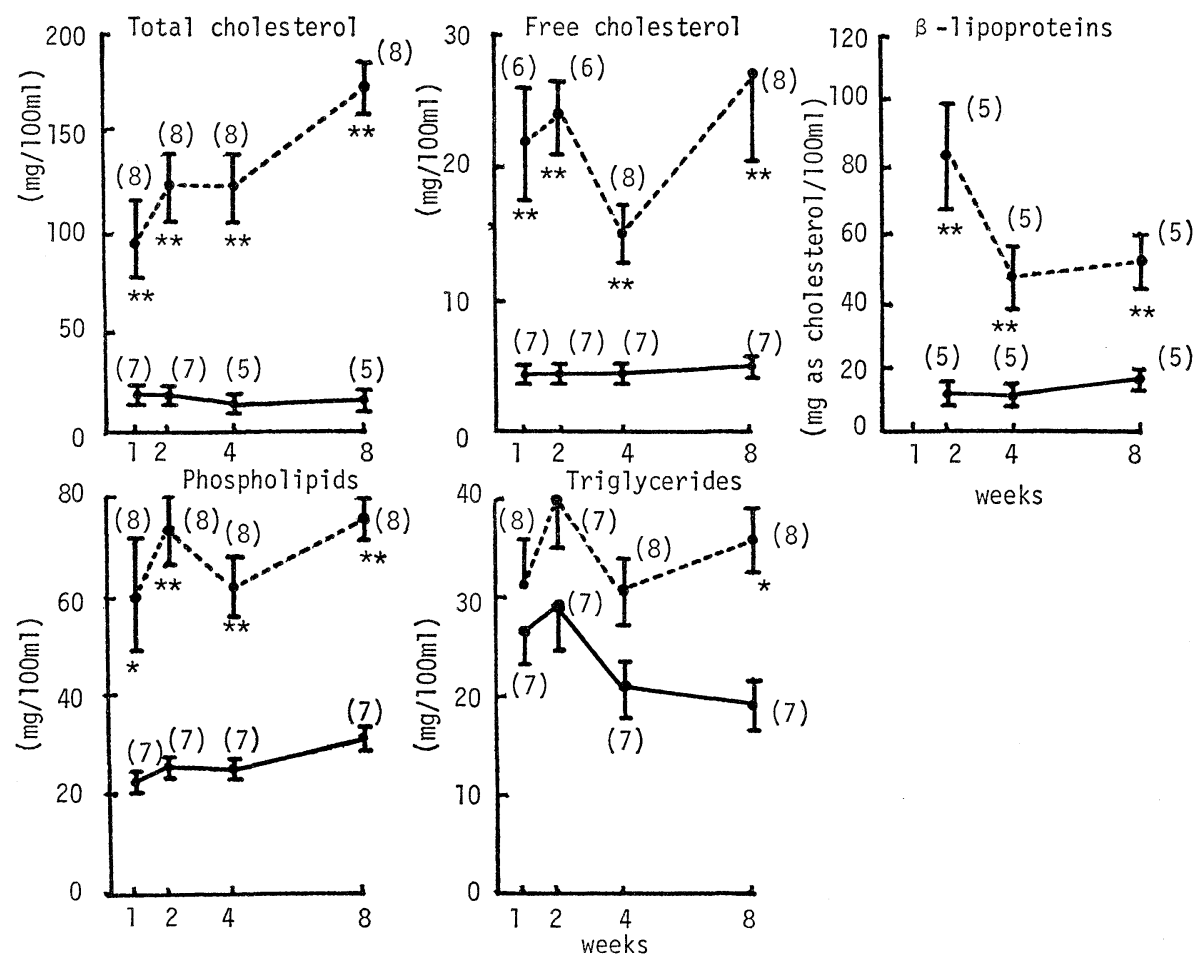

Fig. 4. Effect of dietary cholesterol on plasma lipid levels in guinea pigs.

control diet; ---@, cholesterol diet. Vertical bars represent standard errors of the means. * and **: Statistically significant from control values with $P<0.05$ and $P<0.01$, respectively. Figures in parentheses show the number of animals used.

concentration of ADP to induce platelet aggregation using a light microscope (4), the platelet retention test on a glass bead column (25) and the microphotometric method which involves a rotating coneplate, rheoscope, under dark field illumination (5).

Our experiments with guinea pigs using the turbidimetric method (6) demonstrated that a simple addition of cholesterol to a control diet reduced a ADP concentration which induced $50 \%$ incidence of irreversible aggregation of platelets.

An increase of platelet aggregation induced by ADP was further investigated with platelet-plasma crossover experiments (Fig. 3). When platelets from guinea pigs fed a control diet were exposed to plasma from cholesterol-fed animals, there was a notable increase of platelet aggregation in comparison with plasma from animals fed on a control diet. Similar studies were performed by using platelets from cholesterol-fed animals; thereupon an increase of platelet aggregation was also observed, when the platelets were mixed with the plasma from not only animals fed on a cholesterol diet but also animals fed on a control diet. These 

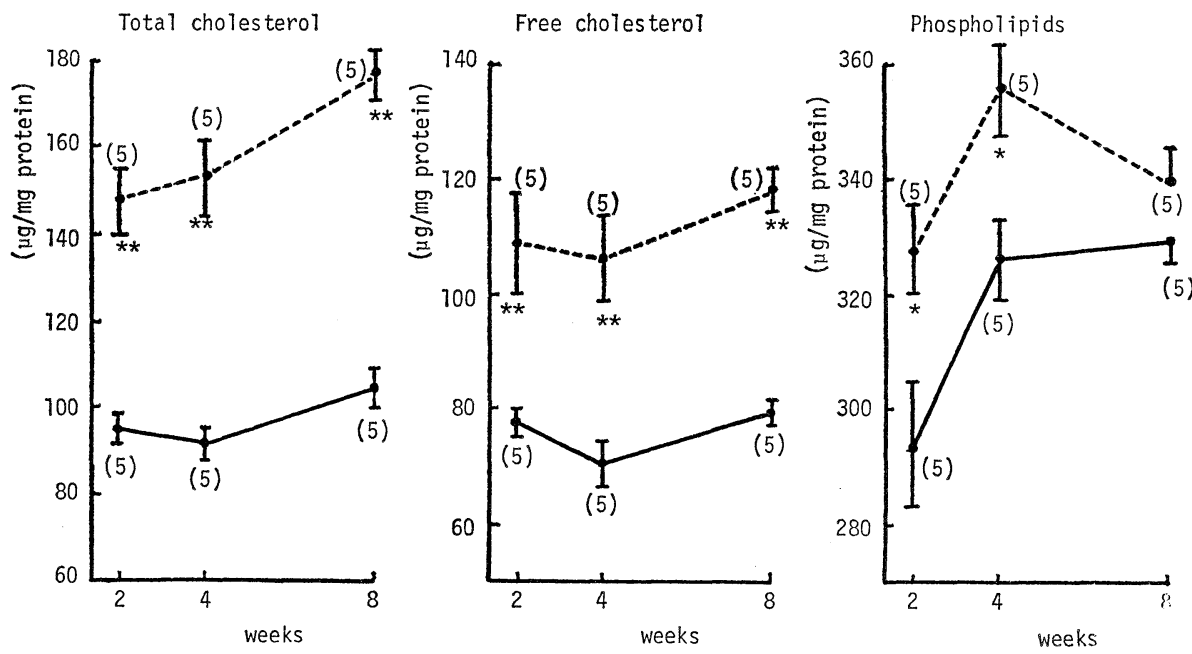

Fig. 5. Effect of dietary cholesterol on platelet lipid contents in guinea pigs. diet; ---- cholesterol diet. Vertical bars represent standard errors of the means. * and **: Statistically significant from control values with $P<0.05$ and $P<0.01$, respectively. Figures in parentheses show the number of animals used.

$\cdot \beta-1$ ipoproteins isolated from animals fed on a cholesterol diet

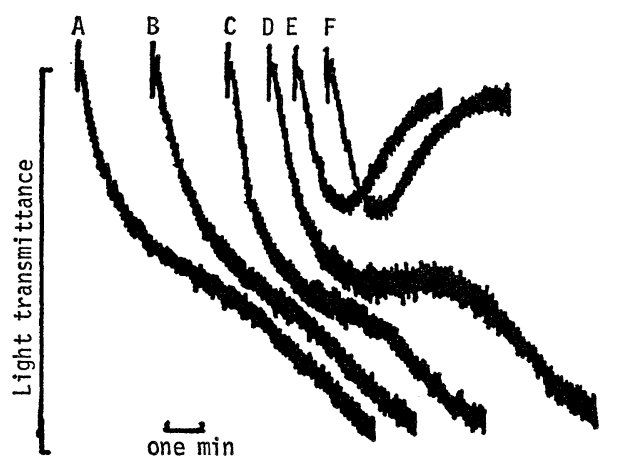

$\beta-1$ ipoproteins isolated from animals fed on a control diet

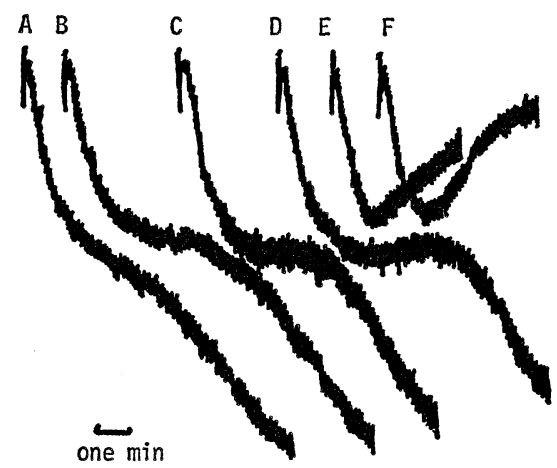

Fig. 6. Enhanching effect of $\beta$-lipoproteins on platelet aggregation induced by ADP $(5 \times$ $10^{-7} \mathrm{M}$ ). Final concentrations of $\beta$-lipoproteins (as cholesterol contents): $\mathrm{A}, 105 \mu \mathrm{g} / \mathrm{ml}$; $\mathrm{B}, 52 \mu \mathrm{g} / \mathrm{ml}$; C, $26 \mu \mathrm{g} / \mathrm{ml} ; \mathrm{D}, 13 \mu \mathrm{g} / \mathrm{ml}$; E, $6.5 \mu \mathrm{g} / \mathrm{ml}$; F, physiological saline.

results suggest that an enhancing factor exists in both plasma and platelets from cholesterol-fed animals.

There is a general agreement that hyperlipemia by fat feeding is an important contributing factor towards thrombus formation $(1,3,26)$. FARBISZEWSKI et al. (27) 
showed that $\beta$-lipoproteins increased platelet aggregation induced by ADP as well as by thrombin, whereas $\alpha$-lipoproteins were inactive and chylomicrons showed an effect only at high concentrations. BoLTON et al. showed a possible explanation for the role of low-density lipoproteins on platelet function; the labilizing effect on platelet membranes was due to the appearance of lysolecithin which came from low-density lipoproteins. KERR et al. (29) observed platelet aggregation by adding phospholipids to PRP; phosphatidic acid, phosphatidylserine and phosphatidylethanolamine caused reversible aggregation, while aggregation caused by sphingomyelin and lysolecithin was irreversible. Fatty acids also exerted a direct influence on platelet aggregation; long-chain saturated fatty acids were more potent than unsaturated fatty acids, when added to PRP $(30,31)$. It is well known that hypercoagulable state in hyperlipemia is often observed and is highly susceptible to thrombosis which seems to be initiated by platelet aggregation (32). Thus, there are many factors which trigger off or enhance platelet aggregation in hyperlipemia.

It should be noted in our experiments that animals fed on a cholesterol diet had a marked increase of cholesterol (total and free) levels in plasma and platelets, and $\beta$-lipoprotein levels in plasma (Fig. 4). Phospholipid contents in plasma increased notably in animals fed on a cholesterol diet but those in platelets increased significantly only at the feeding period from the 2 nd to 4 th week. FFA levels in plasma and platelets from cholesterol-fed animals showed an increasing tendency which was not significant statistically as compared with those from animals fed on a control diet. Changes of saturated and unsaturated fatty acids were not characteristic to account for their effects on platelet aggregation (Table 1). Plasma TG levels in cholesterol-fed animals were significantly higher than in animals fed on a control diet only at the 8 th week of feeding $(P<0.05)$. The hematocrit values, number of platelets and clotting tests such as PT, RCT and Stypven time showed no significant differences between animals fed on a cholesterol and a control diet, though fibrinogen levels were significantly elevated at the feeding period from the 2 nd to 4 th week.

RENAUD et al. (32) have reported the increase in susceptibility of platelets to aggregation, particularly by thrombin, and the shortening of RCT concomitant with the marked increase of serum cholesterol in rats fed on a high butter diet. In the results of present experiments, changes of RCT were not statistically significant. The reason for this difference in RCT is considered largely due to the different contents of diets given to animals, and plasma cholesterol levels thus attained may also have an important role for the change in RCT. A direct relationship has not been known between the increase in susceptibility of platelets to aggregation and the shortening in RCT.

As cholesterol levels in both plasma and platelets increased markedly, it is probable that the increase of cholesterol in plasma may be responsible for the increase of platelet aggregation. Cholesterol in plasma exists mainly in $\beta$-lipo- 
protein fraction. Therefore, $\beta$-lipoproteins in plasma from animals fed both on a cholesterol and a control diet were isolated to test the effect on platelet aggregation induced by ADP. The $\beta$-lipoprotein fractions showed a remarkable increase of platelet aggregation, i.e., the additions of $\beta$-lipoproteins to PRP caused typical irreversible platelet aggregation induced by $5 \times 10^{-7} \mathrm{M}$ of ADP which caused only reversible aggregation by itself (Fig. 6). From these experimental results, $\beta$-lipoproteins may play an important role through increasing platelet aggregation in the pathogenesis of atherosclerosis.

The results of this study indicate that cholesterol feeding enhances platelet aggregation accompanied by a wide range of changes in lipid metabolisms, and one of the causative factors to increase platelet aggregation is assumed to be $\beta$-lipoproteins. Further experiments, however, would be necessary to elucidate whether the effect observed here can only be attributed to the molecule of $\beta$ lipoproteins itself or the cholesterol other than in $\beta$-lipoproteins play an additional role in this connection.

\section{REFERENCES}

1) Renaud, S., Kuba, K., Goulet, C., Lemire, Y., and Allard, C. (1970): Relationship between fatty acid composition of platelets and platelet aggregation in rat and man. Circ. Res., 26, 553-564.

2) Nordøy; A., and RøSET, J. M. (1971): The influence of dietary fats on platelets in man. Acta Med. Scand., 190, 27-34.

3) Renaud, S. (1974): Dietary fats and arterial thrombosis. Thromb. Res., 4, 25-35.

4) Sano, T., Yamasaki, H., and Shimamoto, T. (1973): Enhancement of ADP-induced platelet aggregation by cholesterol and its prevention by pyridinolcarbamate. Thromb. Diathes. Haemorrh., 29, 684-693.

5) Oversohl, K., Bassenge, E., and Schmid-SchönbeIn, H. (1975): Effect of hyperlipidemia and stress on platelet aggregation in rabbits. Thromb. Res., 7, 481-492.

6) BorN, G. V. R. (1962): Aggregation of blood platelets by adenosine diphosphate and its reversal. Nature, 194, 927-929.

7) Walsh, P. N. (1972): Albumin density gradient separation and washing of platelets and study of platelet coagulant activity. Brit. J. Haematol., 22, 205-217.

8) Folch, J., Lees M., and Sloane-Stanley, G. H. (1957): A simple method for the isolation and purification of total lipides from animal tissues. J. Biol. Chem., 226, 497-509.

9) Deguchi, C., Honda, T., and Kurokawa, I. (1972): Counting technic of blood cells using TOA-microcellcounter (in Japanese). Jpn. J. Clin. Pathol., 20, 99.

10) McGovern, J. J., Jones, A. R., and Steinberg, A. G. (1955): The hematocrit of capillary blood. New Eng. J. Med., 253, 308-310.

11) Quick, A. J. (1935): The prothrombin in hemophilia and in obstructive jaundice. J. Biol. Chem., 109, Lxxiii-Lxxiv.

12) Fujimaki, M. (1972): Recalcification time, in Modern Medical Technology (in Japanese), ed. by Miwa, S., Igaku Shoin Ltd., Tokyo, Vol. 3, pp. 485-486.

13) Speat, T. H., and Cintron, J. (1965): Studies on platelet factor-3 availability. Brit. J. Haematol., 11, 269-275.

14) Sakagami, T., and Zilversmit, D. B. (1962): Dextran sulfate precipitation and ultracentrifugation of lipoproteins from hypercholesterolemic dog serum. J. Lipid Res., 3, 111-116. 
15) KoHN, J. (1957): A new supporting medium for zone electrophoresis. Biochem. J., 65, 9 p.

16) ZAK B. (1957): Simple rapid microtechnic for serum total cholesterol. Am. J. Clin. Pathol., 27, 583-588.

17) Zak, B., Dickenman, R. C., Burnett, W. H., and Cherney, P. J. (1954): Rapid estimation of free and total cholesterol. Am. J. Clin. Pathol., 24, 1307-1315.

18) Henmi, K., Mizuno, S., Takamatsu, S., Tamada, Y., Yamada, Y., Kakuta, E., and SASAKI, K. (1970): The new method for the determination of serum phospholipid using permanganate as the oxidizing agent (in Japanese). Igaku No Ayumi, 75, 493-496.

19) VAN HANDel, E., and Zilversmit, D. B. (1957): Micromethod for the direct determination of serum triglycerides. J. Lab. Clin. Med., 50, 152-157.

20) Lowry, O. H., Rosebrough, N. J., Farr, A. L., and Randall, R. J. (1951): Protein measurement with the Folin phenol reagent. J. Biol. Chem., 193, 265-275.

21) Fujimaki, M., (1972): Measurement method of blood coagulation factors, in Modern Medical Technology (in Japanese), ed. by Miwa, S., Igaku Shoin Ltd., Tokyo, Vol. 3, pp. 497-498.

22) Freid, R., and Hoeflmayr, J. (1963): Eine einfache indirekte Bestimmungs-methode der B-Lipoproteide. Klin. Wochschr., 41, 246.

23) Schlierf, G., and Wood, P. (1965): Quantitative determination of plasma free fatty acids and triglycerides by thin-layer chromatography. J. Lipid Res., 6, 317-319.

24) Mustard, J. F., and Packham, M. A. P., (1975): The role of blood and platelets in atherosclerosis and the complications of atherosclerosis. Thromb. Diathes. Haemorrh., 33, 444 456.

25) Mathues, J. K., Wolff, C. E., Cevallos, W. H., and Holmes, W. L. (1968): Platelet adhesiveness and thrombosis in rabbits on an atherogenic diet. Med. Exp., 18, 121-128.

26) Nordøy, A., Hamlin, J. T., Chandler, A. B., and Newland, H. (1968): The influence of dietary fats on plasma and platelet lipids and ADP induced platelet thrombosis in the rat. Scand. J. Haematol., 5, 458-473.

27) FARbiszewski, R., Skrzydlewski, Z., and Worowski, K. (1969): The effect of lipoprotein fractions on adhesiveness and aggregation of blood platelets. Thromb. Diathes. Haemorrh., 21, 89-92.

28) Bolton, C. H., Hampton, J. R., and Mitchell, J. R. A. (1967): Nature of the transferable factor which causes abnormal platelet behaviour in vascular disease. Lancet, 2, 1101-1105.

29) Kerr, J. W., Pirrie, R., MacAulay, I., and Bronte-Stewart, B. (1965): Platelet aggregation by phospholipids and free fatty acids. Lancet, 1, 1296-1299.

30) Mahadevan V., Singh, H., and Lundberg, W. O. (1966): Effects of saturated and unsaturated fatty acids on blood platelet aggregation in vitro. Proc. Soc. Exp. Biol. Med., 121, 82-85.

31) Hoak, J. C., Warner, E. D., and Connor, W. E. (1967): Platelets, fatty acids and thrombosis. Circ. Res., 20, 11-17.

32) RenAud, S., and Lecompte, F. (1970): Hypercoagulability induced by hyperlipemia in rat, rabbit and man. Circ. Res., 27, 1003-1011. 